\title{
Reconstructing winter climate anomalies in the Euro-Atlantic sector using circulation patterns
}

\author{
Erica Madonna ${ }^{1}$, David S. Battisti ${ }^{2}$, Camille $\mathrm{Li}^{1}$, and Rachel H. White ${ }^{3}$ \\ ${ }^{1}$ Geophysical Institute, University of Bergen and Bjerknes Centre for Climate Research, Bergen, Norway \\ ${ }^{2}$ Department of Atmospheric Sciences, University of Washington, Seattle, WA, USA \\ ${ }^{3}$ Department of Earth, Ocean and Atmospheric Sciences, University of British Columbia, Vancouver, BC, Canada
}

Correspondence: Erica Madonna (erica.madonna@uib.no)

Received: 25 January 2021 - Discussion started: 28 January 2021

Revised: 11 June 2021 - Accepted: 29 June 2021 - Published: 25 August 2021

\begin{abstract}
The efficacy of Euro-Atlantic circulation regimes for estimating wintertime climate anomalies (precipitation and surface temperature) over Europe is assessed. A comparison of seasonal climate reconstructions from two different regime frameworks (cluster analysis of the low-level zonal flow, and traditional blocking indices) is presented and contrasted with seasonal reconstructions using the North Atlantic Oscillation (NAO) index. The reconstructions are quantitatively evaluated using correlations and the coefficient of efficiency, accounting for misfit in phase and amplitude. The skill of the various classifications in reconstructing seasonal anomalies depends on the variable and region of interest. The jet and blocking regimes are found to capture more spatial structure in seasonal precipitation anomalies over Europe than the NAO, with the jet framework showing generally better skill relative to the blocking indices. The reconstructions of temperature anomalies have lower skill than those for precipitation, with the best results for temperature obtained by the NAO for high-latitude and by the blocking framework for southern Europe. All methods underestimate the magnitude of seasonal anomalies due to the large variability in precipitation and temperature within each classification pattern.
\end{abstract}

\section{Introduction}

Seasonal precipitation and temperature anomalies over Europe exhibit large year-to-year variability, with direct societal impacts such as on crop yields and renewable energy production (Grams et al., 2017; Jerez et al., 2013; Lesk et al.,
2016). The seasonal climate signal results from a succession of daily weather that is often organized by the large-scale flow into a finite number of preferred circulation patterns, also called regimes (Corte-Real et al., 1995; Molteni et al., 1990; Vautard, 1990). Therefore, one might expect that seasonal climate anomalies could be reconstructed from the frequency of the dominant atmospheric patterns over a season. This approach has been used to study future trends in $\mathrm{Eu}-$ ropean precipitation (Santos et al., 2016) and as a predictor for droughts (Lavaysse et al., 2018). It can also be used to better understand and anticipate the changes in weather patterns that sum to the seasonal to decadal climate anomalies that stem from predictable changes in the atmosphere-ocean system, such as those associated with the El Niño-Southern Oscillation phenomenon and the Atlantic multidecadal variability associated with the ocean overturning circulation in the North Atlantic (see Battisti et al., 2019, for a review).

Atmospheric variability patterns can be characterized in several ways, such as by the North Atlantic Oscillation index (NAO, e.g. Hurrell, 1995), the occurrence of blocking (e.g. Pfahl and Wernli, 2012; Sillmann and Croci-Maspoli, 2009; Trigo et al., 2004), and the configuration of the North Atlantic jet stream (Woollings et al., 2010; Madonna et al., 2017). All these complementary classifications have been shown to be able to capture specific aspects of the wintertime climate over Europe, but there has been to our knowledge no direct comparison of the skill of these classifications in reconstructing seasonal climate.

In this study we compare how well European winter conditions are described by indices of the NAO, blocking, and North Atlantic jet configurations. The NAO manifests as sea 


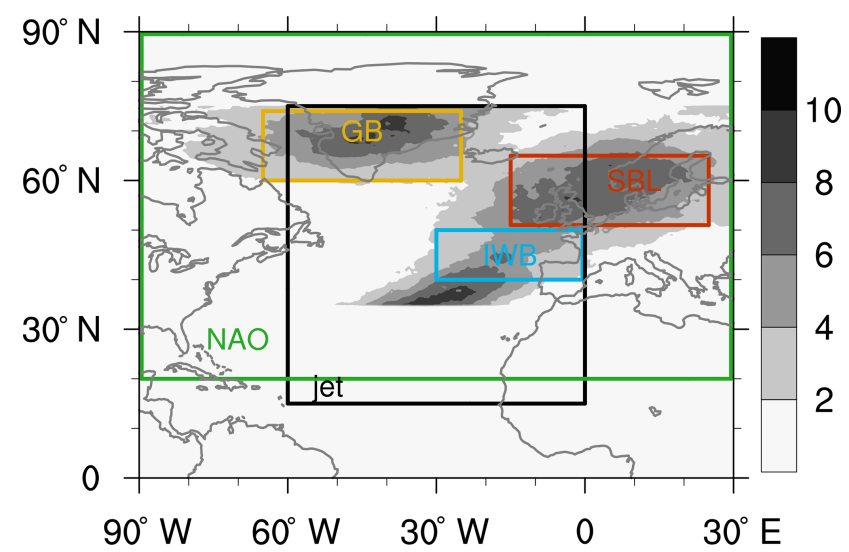

Figure 1. Winter (DJF) blocking climatology (shading, as \% of time). The green and black boxes show the domain used for the definition of the NAO and jet clusters, respectively. The orange, blue, and red boxes denote the regions used for Greenland blocking (GB), Iberian wave breaking (IWB), and Scandinavian Blocking (SBL), respectively.

level pressure (SLP) fluctuations with anticorrelated extrema between two poles: one over the Azores and one over Iceland. These fluctuations signify changes in the prevailing westerly winds and in the propagation path of storms into Europe (e.g. Hurrell, 1995; Hurrell et al., 2003; Qian et al., 2000; Rogers, 1997; Wanner et al., 2001). In contrast, blocking is the presence of a persistent and stationary high-pressure system that obstructs or deviates the westerly flow (Rex, 1950). In the North Atlantic sector blocking occurs mainly over three regions: Greenland, Scandinavia, and the Iberian Peninsula (Treidl et al., 1981; Davini et al., 2014, also shown in Fig. 1). Precipitation is reduced within the blocked region (Sousa et al., 2017) while cold temperature extremes are often observed southeast of the blocked region (Sillmann and CrociMaspoli, 2009). Lastly, jet configurations describe preferred flow paths of the North Atlantic jet stream, which acts as waveguide for midlatitude storms (Athanasiadis et al., 2010; Hoskins and Ambrizzi, 1993; Wettstein and Wallace, 2010; Wirth et al., 2018). In winter the North Atlantic jet stream can assume five different configurations (southern, central, northern, tilted, and mixed, Madonna et al., 2017) with distinct patterns of storm propagation, all of which are associated with regional climate anomalies over Europe.

The three classification methods for circulation regimes that we use in this study are not independent: the strength and position of the jet are intrinsically linked to changes in SLP and thus to the NAO and blocking; blocking over Greenland, Scandinavia, and the Iberian Peninsula correspond to a southern, mixed, and northern configuration of the jet stream, respectively (Madonna et al., 2017). However, the NAO does not map clearly onto distinct jet configurations or blocking patterns, with the positive phase being especially ambiguous
(Woollings et al., 2010; Davini et al., 2014; Madonna et al., 2017).

These classifications of North Atlantic atmospheric variability thus offer closely related but alternative views of seasonal climate fluctuations. For example, an extreme season may occur due to the unusual persistence or frequency of a certain jet configuration (Madonna et al., 2019), without a corresponding extreme value of the NAO index or blocking pattern. This study aims to compare the ability of three classification methods (NAO, blocking, jet configurations) to reconstruct seasonal climate anomalies over Europe. By knowing the frequency of each circulation pattern, we assess the skill of each method to reproduce the sign (i.e. correlation) and amplitude (i.e. ratio of standard deviations) of seasonal precipitation and temperature anomalies.

\section{Methods and data}

We focus on the low-level wind (900 to $700 \mathrm{hPa}$ ), $2 \mathrm{~m}$ temperature $(\mathrm{T} 2 \mathrm{~m})$, and total precipitation. The analyses are conducted for winter (DJF; the $90 \mathrm{~d}$ period 1 December28 February), with ERA-Interim reanalysis (Dee et al., 2011) for the period 1979-2014, interpolated to a $0.5^{\circ}$ horizontal resolution. To identify blocking, 6-hourly data of geopotential height at $500 \mathrm{hPa}$ are used. For the rest of the analysis, daily means are used.

\subsection{Classifications}

\subsubsection{NAO}

We use the daily NAO time series from NOAA (downloaded from ftp://ftp.cpc.ncep.noaa.gov/cwlinks/norm.daily. nao.index.b500101.current.ascii, last access: 14 May 2020), which is calculated using geopotential height at $500 \mathrm{hPa}$ and covers the whole North Atlantic basin north of $20^{\circ} \mathrm{N}$ (green box in Fig. 1). A day is classified as a positive (negative) NAO day if its NAO value is above 0.5 (below -0.5) of the wintertime NAO standard deviation. The remaining days, about $35 \mathrm{~d}$ per winter (Table 1), are considered neutral NAO days.

\subsubsection{Blocking}

Blocking events are identified on 6-hourly data following the criteria from Scherrer et al. (2006), which define a block as a reversal in the meridional gradient of the geopotential height at $500 \mathrm{hPa}$ in a $30^{\circ}$ latitudinal band that lasts for at least $5 \mathrm{~d}$. Climatologically in the North Atlantic there are three main regions affected by blocking (shading in Fig. 1): one over Greenland, one over northern Europe/Scandinavia, and one offshore of the Iberian Peninsula. Note that the enhanced frequency at $30^{\circ} \mathrm{N}$ is an artefact of the detection method (see discussion in Davini et al., 2014). We define three boxes to capture these three regions: Greenland $\left(65-25^{\circ} \mathrm{W}, 60-75^{\circ} \mathrm{N}\right.$, 
Table 1. Average and (in brackets) standard deviation of the number of days per winter in each category. The positive (negative) NAO phase is defined as days with NAO values above 0.5 (below -0.5) of the time series standard deviation (see Sect. 2 for more information), and the remaining days are considered as neutral. We differentiate between blocking over Greenland (GB), over the Iberian Peninsula (IWB), Scandinavia (SBL) and non-blocked days (NB). The categories for the jet are south (S-jet), tilt (T-jet), north (N-jet), mixed (M-jet), and central (C-jet). We also reported the number of days in the undefined category using the jet classification (undef).

\begin{tabular}{lr|lr|lr}
\hline \multicolumn{2}{c|}{ NAO } & \multicolumn{2}{|c|}{ Blocking } & \multicolumn{2}{c}{ Jet } \\
\hline NAO- & $25.4(16.8)$ & GB & $13.5(11.4)$ & S-jet & $7.3(7.7)$ \\
NAO+ & $30.0(13.9)$ & & & T-jet & $12.0(9.8)$ \\
& & IWB & $13.0(12.3)$ & N-jet & $8.6(7.5)$ \\
& & SBL & $16.9(9.3)$ & M-jet & $9.7(7.4)$ \\
& & & & C-jet & $10.9(11.0)$ \\
\hline neutral & $34.6(11.1)$ & NB & $51.9(14.0)$ & undef & $41.4(10.0)$ \\
\hline
\end{tabular}

GB, orange box in Fig. 1), Scandinavia $\left(15^{\circ} \mathrm{W}-25^{\circ} \mathrm{E}, 50\right.$ $65^{\circ} \mathrm{N}$, SBL, red box), and offshore of the Iberian Peninsula $\left(30^{\circ} \mathrm{W}-0^{\circ}, 40-50^{\circ} \mathrm{N}\right.$, named as in Davini et al. (2014) Iberian wave breaking (IWB), blue box).

A day is considered a blocked day if at least $10 \%$ of the grid points in the respective box satisfy the blocking criteria. This choice reduces the number of blocking events identified as it detects blocking episodes at a later stage of their development (i.e. when they are spatially larger) than if no threshold were applied, and avoids the detection of blocks that are predominantly located upstream or downstream of the boxed regions. Table 1 reports the average (standard deviation) number of days per winter with blocking at different locations. During the 35 winters, we detect on average $13.5 \mathrm{~d}$ per winter of GB, 16.9 of SBL, and 13.0 of IWB while $51.9 \mathrm{~d}$ are considered as "non blocked" (NB). It can occasionally happen that during a single day several regions are simultaneously blocked. Therefore, the sum of blocking and NB days does not sum to exactly $90 \mathrm{~d}$ (i.e. one winter).

\subsubsection{Jet clusters}

Cluster analysis applied to SLP or geopotential height is commonly used to classify circulation patterns into so-called weather regimes. In the North Atlantic during winter, four classical regimes are identified (e.g Cassou, 2008; Michelangeli et al., 1995; Vautard, 1990), although the optimal number of clusters is not clear-cut and depends somewhat on the algorithm, atmospheric field, domain, and considered temporal period (Christiansen, 2007; Dorrington and Strommen, 2020; Falkena et al., 2020; Woollings et al., 2010). Madonna et al. (2017) showed that applying a cluster analysis to the low-level jet leads to four jet configurations that correspond to the four classical weather regimes in the Euro-Atlantic sector: the northern jet resembles the Atlantic Ridge regime, the central jet resembles the zonal/NAO+ regime, the mixed jet resembles the Scandinavian blocking regime, and the southern jet resembles the Greenland anticyclone/NAOregime (see Fig. 8 in Madonna et al., 2017). Using five clusters, the zonal regime can be further separated into a central and tilted jet (see Fig. 10 in Madonna et al., 2017). In this study, we use five jet clusters, which gives more distinct jet configurations over the North Atlantic.

We calculate the daily mass-weighted average zonal wind $(U)$ between $900-700 \mathrm{hPa}$ in the sector $60^{\circ} \mathrm{W}-0^{\circ}, 15-75^{\circ} \mathrm{N}$ (black box, Fig. 1) and use this field to calculate jet clusters as described in Madonna et al. (2017). We perform an EOF analysis on the low-level wind to reduce the dimensions and apply a $k$-means clustering algorithm to the first five principal components, which explains up to $80 \%$ of the wintertime variability in that sector.

Every day is associated with a cluster depending on the normalized inverse Euclidean distance $(d)$ from the cluster centroid (i.e. $d=1$ at the centroid location and $d=0$ far from the centroid) in the five-dimensional space of the principal components. The Euclidean distance $(E)$ from the centroid $c$ for a point $x$ in a $n$-dimensional space is defined as $E(c, x)=\sqrt{\sum_{i=1}^{n}\left(c_{i}-x_{i}\right)^{2}} . E$ is normalized such that the proximity measure $d=1 / E$ sums to 1 over all days. Since some days can be close to more than one centroid, in particular during transition days from one cluster to the other, we keep only days whose $d$ to the respective centroid is larger than 0.5. A sensitivity analysis suggests that the choice of the threshold $d$ does not have a significant impact on the results (see Supplement). Approximately $54 \%$ of the 3150 $(=35 \times 90) \mathrm{d}$ are unequivocally attributed to a specific cluster (see Table 1, 41.4 d, i.e. $46 \%$ are not assigned to any cluster).

The five clusters represent a southern jet (S-jet), a central jet (C-jet), a northern jet ( $\mathrm{N}$-jet), a tilted jet (T-jet), and a mixed jet (M-jet with a split structure). On average each cluster occurs between $7.3 \mathrm{~d}$ (S-jet) and $12.0 \mathrm{~d}$ (T-jet) per winter, as reported in Table 1, with large winter-to-winter variability (standard deviation).

\subsubsection{Associated weather anomalies}

Each NAO phase, blocking category, and jet cluster is characterized by different circulation, precipitation, and temperature anomalies. We compute daily anomalies of zonal wind, precipitation, and temperature and then construct composites for each NAO phase, blocking category, and jet cluster by averaging the daily fields of all (defined) days belonging to the corresponding category. For wind and precipitation the daily anomalies are calculated by subtracting the climatological 35-year winter mean, as previous studies have shown a weak seasonal cycle of those variables within DJF (Woollings et al., 2014; Zveryaev, 2004). However, the seasonal cycle is much stronger for temperature and therefore temperature anomalies are calculated by removing the daily 
35 -year average, smoothed with a $30 \mathrm{~d}$ running mean. The resulting anomalies are presented in Sect. 3.1.

\subsection{Seasonal reconstructions}

To reconstruct the seasonal anomalies we count the number of days in each NAO phase, blocking category, and jet cluster for each winter. Similar to Cortesi et al. (2019), we then reconstruct the seasonal precipitation and temperature anomaly maps $A_{\text {rec }}(\phi, \lambda, t)$ for each season $(t)$ as follows:

$A_{\mathrm{rec}}(\phi, \lambda, t)=\sum_{i}\left(Y_{i}(\phi, \lambda) \cdot f_{i}(t)\right)$,

where $\phi, \lambda$, and $t$ are latitude, longitude, and time, respectively; $i$ represents the two NAO phases, three blocking categories, or five jet clusters; $Y_{i}(\phi, \lambda)$ are the maps of seasonal average precipitation/temperature anomalies associated with the considered pattern; $f_{i}(t)$ is the fraction of time the pattern occurs in the given season $t$ (i.e. $f_{i}(t)=\frac{\text { \#days of pattern } i}{\text { \#days per season }(=90)}$ ).

For example for the jet clusters in DJF 2013/14 (cf. Fig. 5), there are $0 \mathrm{~d}$ classified as $\mathrm{S}$-jet and $\mathrm{M}$-jet, $11 \mathrm{~d}$ as T-jet, $7 \mathrm{~d}$ as $\mathrm{N}$-jet, and $60 \mathrm{~d}$ as $\mathrm{C}$-jet. The remaining $12 \mathrm{~d}$ belong to the undefined category and are not used. The reconstructed anomaly using the jet clusters for DJF 2013/14 is

$A_{\mathrm{rec}}(\phi, \lambda, 2013 / 14)=$
$\frac{0 \cdot Y_{S}(\phi, \lambda)+0 \cdot Y_{M}(\phi, \lambda)+11 \cdot Y_{T}(\phi, \lambda)+7 \cdot Y_{N}(\phi, \lambda)+60 \cdot Y_{C}(\phi, \lambda)}{90}$,

where the $Y_{i}(\phi, \lambda)$ are the composite maps of precipitation or temperature anomalies, and the subscript stands for the jet type.

This reconstruction method assumes that the average of the undefined days represents the climatological mean; i.e. the average anomaly field associated with undefined days is close to zero. In the Supplement (Fig. S1) we show that this is indeed the case. In the case of the residual not summing to zero, Eq. (1) must be modified to include the pattern and the fraction of time of the unclassified days. To compare the ability of each classification method to reconstruct seasonal anomalies, we compute at each grid point the correlation as well as the coefficient of efficiency (CE, described in the next section) between the reconstructed and the observed (ERAInterim) seasonal anomalies.

\subsubsection{Coefficient of efficiency (CE)}

Assume $o$ is the observed quantity and $p$ is the reconstructed quantity. The coefficient of efficiency (CE) (Nash and Sutcliffe, 1970; see also Bürger, 2007; Briffa et al., 1992; Wang et al., 2014), which we calculate at each grid point $(\phi, \lambda)$, is given by
$\mathrm{CE} \equiv 1-\frac{\sum_{t}\left(o_{t}-p_{t}\right)^{2}}{\sum_{t}\left(o_{t}-\bar{o}\right)^{2}}$,

where $\overline{(~)}$ denotes the mean of a quantity and the sum is over all winter seasons $(t)$.

Equation (3) can be rewritten as

$\mathrm{CE} \equiv 1-\frac{\sigma^{2}\left(o^{\prime}\right)+\sigma^{2}\left(p^{\prime}\right)-2<o^{\prime}, p^{\prime}>/ N+(\bar{o}-\bar{p})^{2}}{\sigma^{2}\left(o^{\prime}\right)+\bar{o}^{2}}$,

where $\left({ }^{\prime}\right)$ denotes the anomaly about the mean $\overline{()}$ and $\sigma$ is the standard deviation.

If we consider only anomalies and therefore assume that the mean of $o$ and $p$ are both zero, the equation can be simplified such that

$\mathrm{CE} \equiv 2 r a-a^{2}$,

where $a$ is an amplitude ratio of the standard deviations of the time series,

$a=\frac{\sigma(p)}{\sigma(o)}$,

and $r$ is the correlation between $o$ and $p$.

In our case, $o$ is the observed anomaly of precipitation/temperature and $\bar{o}$ is by definition zero, while $p$ is the reconstructed anomaly and $\bar{p}$ is not necessarily zero (see Fig. S2). In this study, the CE is calculated using Eq. (3), while the simplification (Eq. 5) is used for scaling the anomaly amplitudes (see Sect. 3.3).

When applied to reconstructions and observations, the CE is a measure of skill in reconstruction that is more restrictive than a simple correlation because it penalizes for both phase and amplitude misfits. For a perfect reconstruction, $\mathrm{CE}=1$. For a reconstruction with observed variance $(a=1)$ that is correlated with the observed time series of seasonal anomalies at $r=0.5$, the result is $\mathrm{CE}=0$. For a reconstruction that is perfectly correlated with observations but with twice the observed amplitude, we arrive at the same result of $\mathrm{CE}=0$. We consider $\mathrm{CE}>0.25$ to indicate a good reconstruction. A reconstruction that has perfect variance $(a=1)$ and $\mathrm{CE}=0.25$ would explain $39 \%$ of the observed variance $(r=0.63)$; given 35 years of data (degrees of freedom), this correlation would be significant at $p=0.0001$. For a reconstruction with perfect correlation (i.e. $r=1$ ), $\mathrm{CE}>0.25 \mathrm{can}$ be obtained for amplitude values $0.13<a<1.87$. As the $\mathrm{CE}$ maximizes when $r=a$ (and $\max (\mathrm{CE})=r^{2}$ ), a CE of 0.25 also implies a minimum correlation of 0.5 independent of the amplitude error. For this reason, only points with correlation greater than 0.5 are considered when optimizing the CE (see Sect. 3.3). 

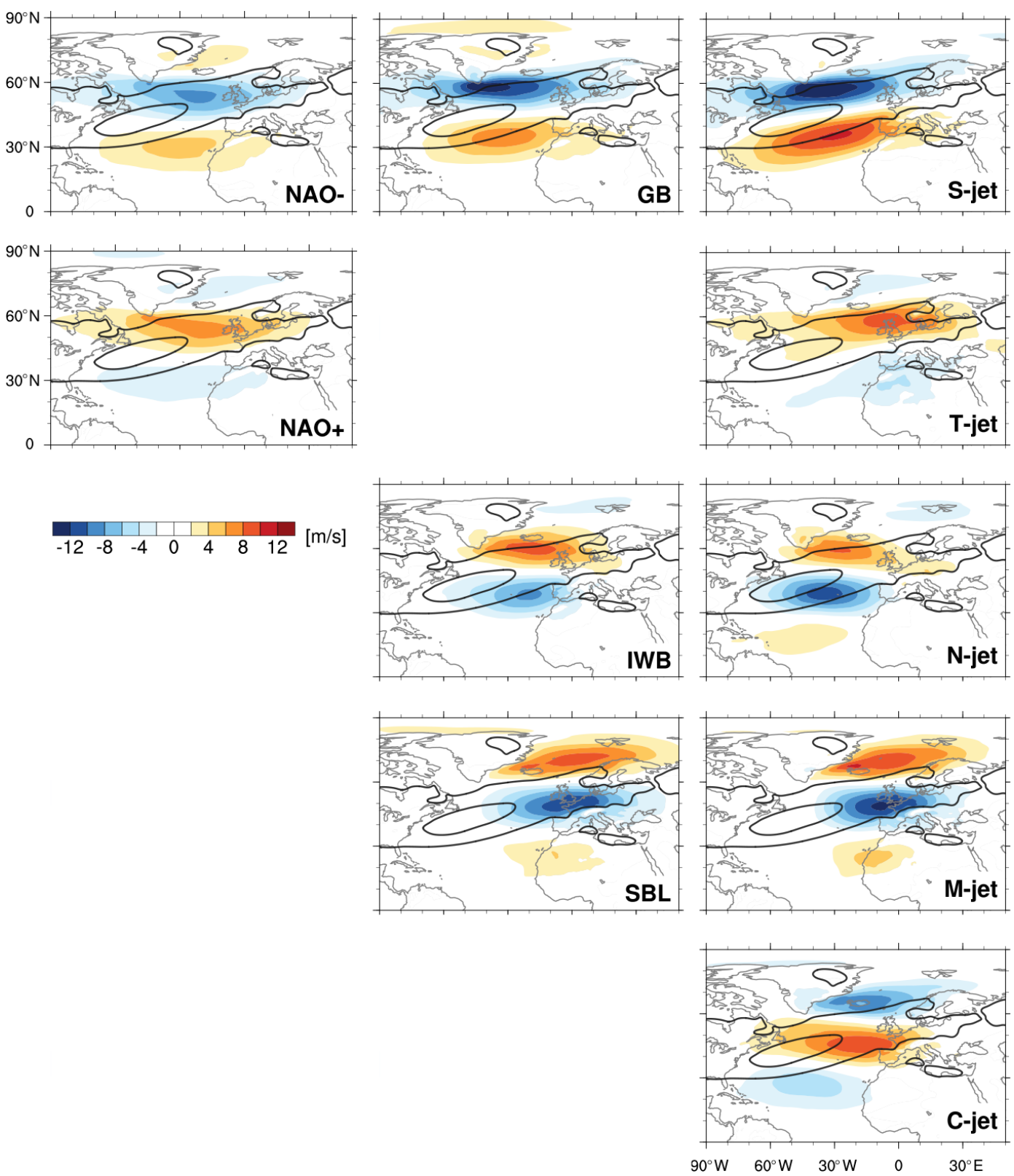

Figure 2. Zonal wind anomalies (shading, in $\mathrm{ms}^{-1}$ ) at $850 \mathrm{hPa}$ for two NAO phases (first column), three blocking categories (second column), and five jet clusters (third column). Black contours show the climatological zonal wind at $850 \mathrm{hPa}$ (contours at 5 and $10 \mathrm{~ms}^{-1}$ ). The figure is organized such that maps in the same row represent similar circulation patterns identified by more than one method (NAO, blocking, jet regime).

\section{Results}

\subsection{Classification of anomalies and interannual variability}

Distinct wind, temperature, and precipitation anomalies are associated with each NAO phase, blocking category, and jet cluster (Figs. 2-4). Figure 2 shows the zonal wind anomalies for each pattern (colours) and the climatological DJF zonal wind distribution (black contours). Figures 3 and 4 show precipitation and temperature anomalies (colours), respectively, and the composite zonal wind (black contours). The panels are arranged such that each row includes "similar" (based on temporal correlation shown in Fig. 5) patterns identified using the NAO index (left column), blocking (centre column), and the jet clusters (right column). In general, wind and temperature patterns along each row are remarkably similar given the composites including different numbers of days; e.g. for the top row, there are on average $25.4 \mathrm{~d}$ per season corresponding to the NAO- group, $13.5 \mathrm{~d}$ 
to GB, and $7.3 \mathrm{~d}$ to S-jet (see Table 1). Despite similarity in the spatial structures of the composites, there can be large differences in the strength of the anomalies for the different classification methods.

The top rows of Figs. 2-4 show a clear correspondence between the negative NAO phase, Greenland blocking (GB), and the S-jet cluster, consistent with previous work (Woollings et al., 2010; Madonna et al., 2017). In all three composites the jet is located southwards of its climatological position (Fig. 2). This southerly shifted jet is also zonally oriented, which can be seen in the total composite wind fields shown in black contours in Figs. 3 and 4. In all three composites, precipitation is enhanced in the jet core and at its ends, e.g. over the Iberian Peninsula (Fig. 3, blue shading). Although the patterns look fairly similar, they differ in intensity, with the highest precipitation anomalies found in the Sjet cluster. When the jet is shifted south (NAO-, GB, S-jet), Greenland is warmer than usual, while northern Europe and the Barents Sea are colder than usual (Fig. 4, shading). The anomaly patterns shown in the top row resemble the Greenland anticyclone/NAO- regime in the framework of the four classical Euro-Atlantic weather regimes (e.g. cf. with Cattiaux et al., 2013; van der Wiel et al., 2019).

There is less correspondence between the positive NAO phase and any other pattern. As the positive NAO phase has often been referred to as the unblocked or unperturbed state (e.g. Woollings et al., 2008, 2010), it does not resemble any of the blocking patterns. The positive NAO composite has wind and temperature anomaly patterns reminiscent of both the tilted and central jet clusters (Figs. 2 and 4, shadings), with a jet shifted to the north (and tilted) and warmer temperatures over central and northern Europe. The warm anomaly over the Barents Sea observed during the positive NAO phase is weakly present in both the tilted and central jet composites, while the cold anomaly over Greenland is linked to the tilted jet rather than the central jet. Also, precipitation anomalies of the positive NAO phase are more similar to the tilted jet cluster than the central jet cluster, indicative of the large change in precipitation pattern associated with the relatively small shifts in jet position.

Blocking over the Iberian Peninsula (IWB) is associated with a northward shift of the jet (N-jet), while blocking over Scandinavia (SBL) splits the jet, resulting in a M-jet configuration (Madonna et al., 2017). Translated into the four classical weather regimes, blocking in these regions thus occurs during the Atlantic Ridge and Scandinavian blocking regimes, respectively (Madonna et al., 2017). The blocked region is drier than climatology for both cases (Fig. 3), with less precipitation offshore and over the Iberian Peninsula associated with the $\mathrm{N}$-jet cluster (IWB), and less precipitation over central Europe associated with the M-jet cluster (SBL). During IWB, southern Europe and northern Africa are colder, while northern Europe is warmer than normal; during N-jet, only the cold anomaly is evident. During SBL, most of Europe is cold and northern Scandinavia is warm.
The zonal wind anomaly composites of the days that are not included in any category are close to zero for the NAO (neutral days) and for the jet (undefined), but not for the nonblocked (NB) category (see Fig. S1). This behaviour can be understood from the point of view of the classical weather regimes, as the non-blocked category includes days that belong to the "zonal/NAO+" regime as well as days with weak wind anomalies. Therefore, in terms of zonal wind, the composite of non-blocked days is very different from climatology. However, this effect is less evident in the precipitation and temperature anomalies (i.e. anomalies close to zero).

The correspondence between the jet and blocking composites extends to seasonal timescales. Figure 5 shows the time series of the occurrence (i.e. the number of days per winter) of each NAO phase, blocking, and jet cluster. The time series of the S-jet cluster has a correlation of 0.64 with GB and 0.67 with the negative NAO phase. However, the S-jet is less frequent than the other two, with on average only $7.3 \mathrm{~d}$ per winter, compared to $13.5 \mathrm{~d}$ of GB and $25.4 \mathrm{~d}$ of the negative NAO phase (Table 1). The $\mathrm{N}$-jet occurs on average $8.6 \mathrm{~d}$ per winter and IWB $13.0 \mathrm{~d}$ (Table 1), and their time series (Fig. 5b) are correlated at 0.71 . The M-jet occurs on average $9.7 \mathrm{~d}$, SBL $16.9 \mathrm{~d}$, and their time series are correlated at 0.58 . The C-jet (10.9d) and T-jet (12.0 d) are the most frequent jet clusters; however, they show a relatively low correlation with the positive NAO time series ( 0.30 and 0.45 , respectively).

The winter to winter differences in the number of days in each jet cluster and blocking type is large: standard deviations are of similar magnitude to the mean values (Table 1). Moreover, about $40 \%-60 \%$ of the days are classified as NAO neutral days, unblocked, or undefined (for the jet cluster). The composites of precipitation and temperature for those categories are similar to climatology, and therefore their patterns are characterized by little anomalies, in particular over the European continent (Fig. S1).

\subsection{Seasonal reconstructions}

Using the method described in Sect. 2.2, we reconstruct seasonal anomalies of temperature and precipitation from each of the three classification methods: the NAO, blocking, and jet clusters. Based on our definitions, for each classification the average number of days per season used for reconstruction is between $38.1 \mathrm{~d}$ (blocking composites) and $55.4 \mathrm{~d}$ (NAO composites; Table 1). We compare our reconstructed seasonal anomalies to the observed anomalies to evaluate the skill of each method for precipitation and temperature.

\subsubsection{Correlation}

The ability of each method to reconstruct seasonal weather anomalies varies greatly with location. To assess this, we calculate for each grid point the correlation coefficient between the time series of seasonal reconstructed anomalies and that of the actual anomalies from the ERA-Interim re- 

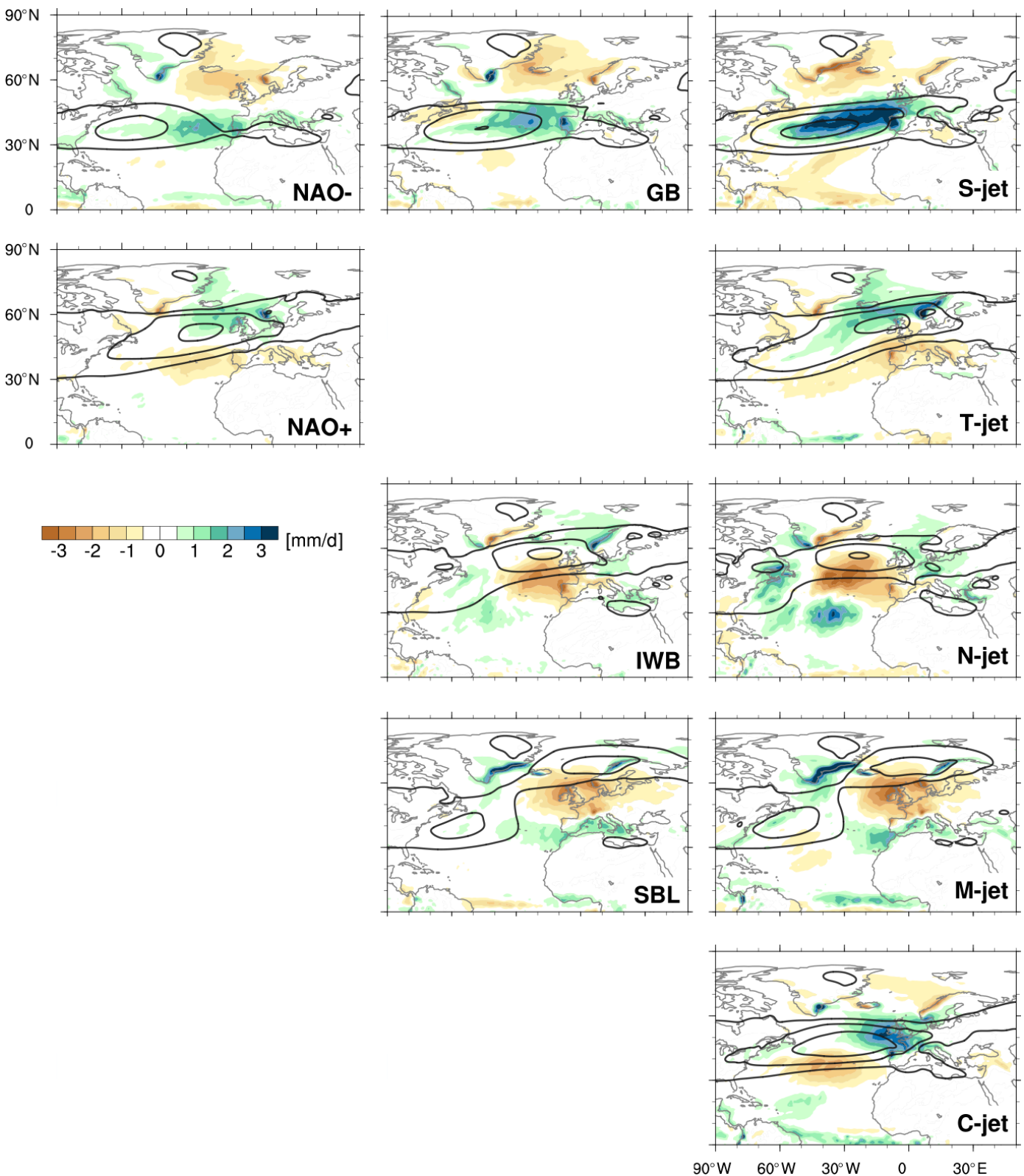

Figure 3. Precipitation anomalies (shading, in $\mathrm{mmd}^{-1}$ ) and zonal wind at $850 \mathrm{hPa}$ (contours at 5,10 , and $15 \mathrm{~ms}^{-1}$ ) for two NAO phases (first column), three blocking categories (second column), and five jet clusters (third column).

analysis. Figure 6 shows the spatial distribution of this correlation coefficient over Europe for precipitation (Fig. 6a, c and e) and temperature (Fig. 6b, d and f); regions are masked with white dots when the correlation coefficient is below 0.5 . The spatial structure of correlations for temperature is much smoother than that for precipitation; this is consistent with smoother variations in temperature fields relative to precipitation, which varies at much smaller spatial scales. For the reconstructions based on jet clusters, precipitation agrees better (higher correlations) with observations than temperature, in particular in regions of high topography. In these regions it is likely that precipitation depends more uniquely on cir- culation than does temperature, as temperature can be affected by other mechanisms including cloud cover and land surface feedbacks. The correlation coefficients for wind are much higher than those of precipitation and temperature for all classifications (Fig. S3).

Overall, the correlations between precipitation reconstructions and observations are higher in western Europe and Scandinavia and lower in central to south-east Europe. Regions with low correlations also show little seasonal variability (i.e. small seasonal standard deviations, Fig. S4) suggesting that large-scale circulation patterns have less impact on precipitation in these regions. There are relatively minor dif- 

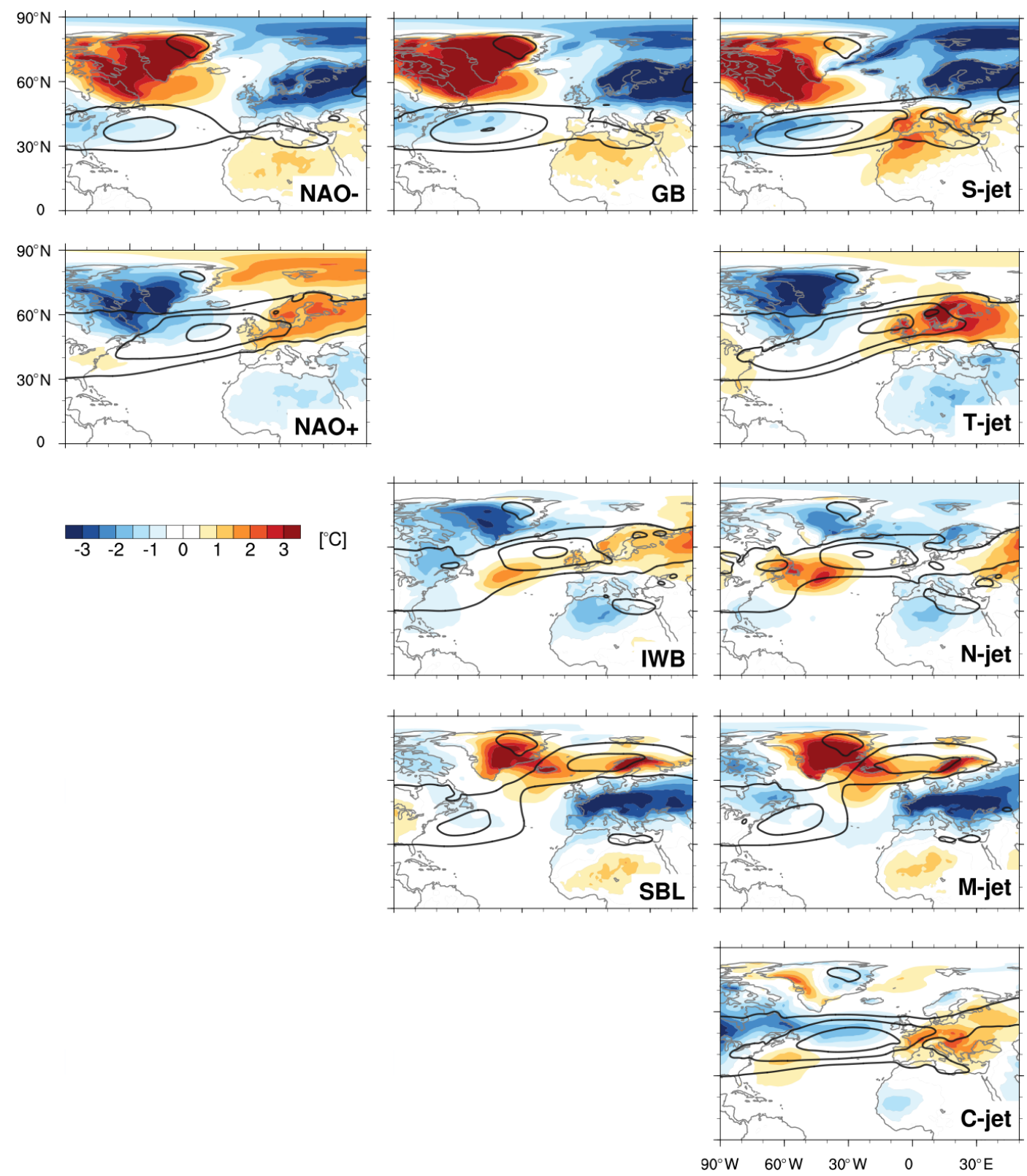

Figure 4. Two-metre temperature anomalies (T2m, shading, in ${ }^{\circ} \mathrm{C}$ ) and zonal wind at $850 \mathrm{hPa}$ (black contours at 5,10 , and $15 \mathrm{~ms}{ }^{-1}$ ) for two NAO phases (first column), three blocking categories (second column), and five jet clusters (third column).

ferences in the correlation of precipitation for the different methods, although correlations over France are noticeably worse in the NAO reconstruction (cf. Fig. 6a with c and e).

The skill of the temperature reconstructions depends greatly on the classification method. Over Spain and France, the blocking method does substantially better than the NAO and slightly better than the jet clusters. Conversely, the NAO performs much better in a band from 50 to $65^{\circ} \mathrm{N}$ than the other methods but substantially worse south of $50^{\circ} \mathrm{N}$. This is consistent with the temperature anomalies in Fig. 4 - neither positive nor negative NAO is associated with strong temperature anomalies across southern Europe. Winter temperature variability exhibits a southwest-northeast gradient (Fig. S4), and regions with larger variability (e.g. Scandinavia) often exhibit larger correlations for all classification methods.

\subsubsection{Coefficient of efficiency}

Having shown strong correlations between reconstructed and observed seasonal anomalies for many regions of Europe, we now examine the coefficient of efficiency (CE), which takes into account both the correlation (i.e. the phase) and the magnitude of the reconstructed values relative to observations. The spatial pattern of the CE for precipitation (Fig. 7) gener- 


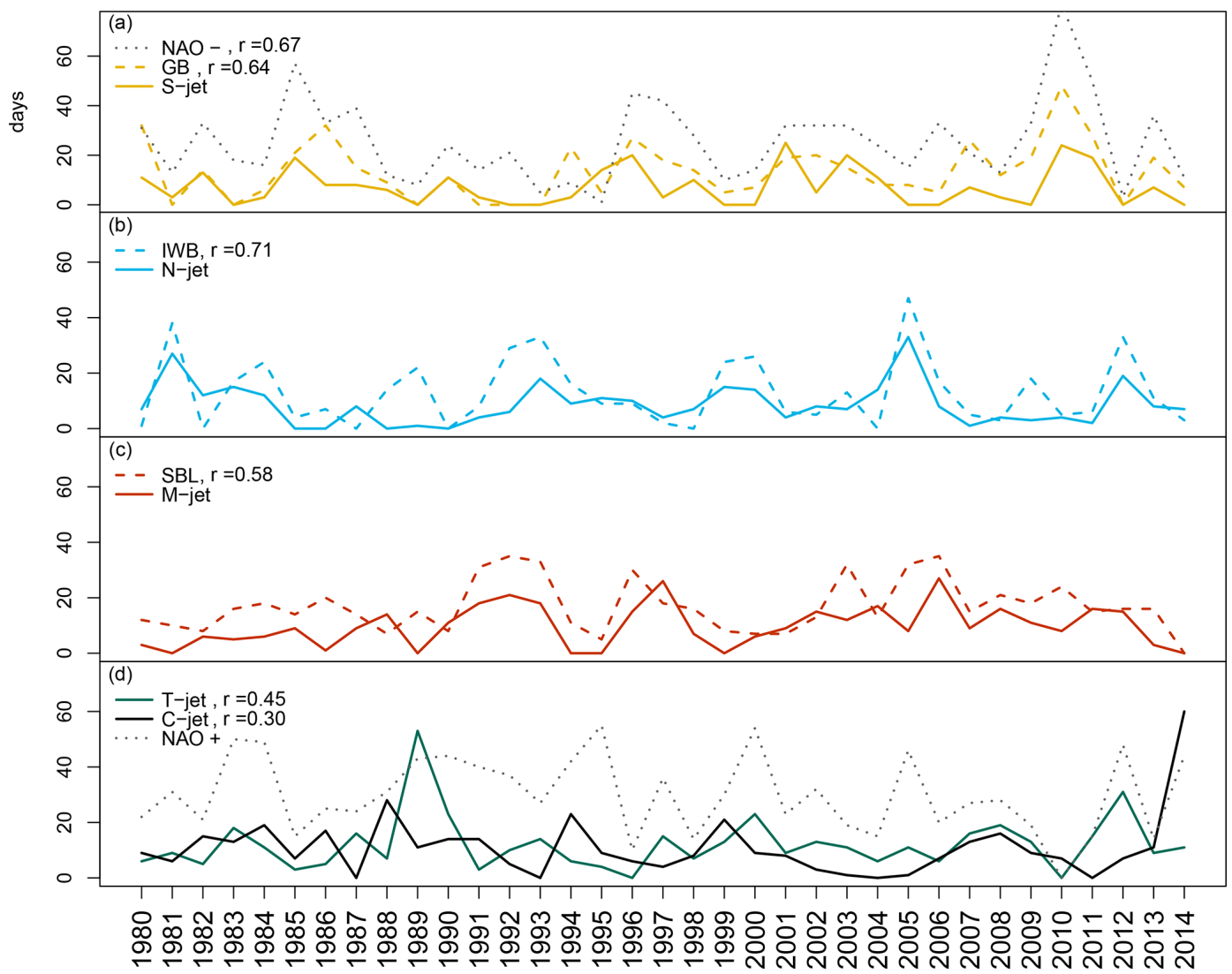

Figure 5. Time series of the number of days per winter for different categories: (a) negative NAO phase (NAO-), Greenland blocking (GB), and S-jet; (b) blocking over Iberia (IWB) and N-jet; (c) blocking over Scandinavia (SBL) and M-jet; and (d) positive NAO phase (NAO+), T-jet, and C-jet. For $(\mathbf{a}-\mathbf{c})$ the correlation $(r)$ between each time series of blocking and jet is shown in the plot. The negative NAO phase has a correlation of 0.67 with S-jet, while the positive NAO phase has correlations of 0.45 with T-jet, 0.30 with $\mathrm{C}$-jet, and 0.31 with $\mathrm{N}$-jet. The year denotes the December-February period; e.g. 2013 is the average for December 2012 to February 2013.

ally follows that of the correlation (Fig. 6), but the absolute values are lower - less than 0.25 across much of the domain. The highest CE values are for the jet classification, in particular over Iberia, France, and Norway, while all methods have low skill over central Europe. Interesting is the poor CE performance for blocking over most of the domain, with even negative $\mathrm{CE}$ values in regions where the correlation is above 0.5 (non-dotted regions). Considering the CE definition expressed by Eq. (4), we see that a non-zero mean of the reconstructed anomalies $(\bar{p})$ can influence the $\mathrm{CE}$ values (note that the mean of the observed anomalies $(\bar{o})$ is by definition zero). The mean reconstructed precipitation $(\bar{p})$ is approximately zero for the NAO and the jet clusters, but not for blocking (Fig. S2), partly explaining the lower performance of the latter classification. Another reason for low CE could be the underestimation of the amplitude of the reconstructed anomalies, as we will discuss later (see Sect. 3.3).

The CE is typically substantially lower for temperature than for precipitation (Fig. 7). The NAO classification does better in northern Europe, while the other two classifications have more skill in southern Europe, in particular over Iberia.
For purposes of applicability, we focus on land regions over Europe. In Fig. S5 we show plots that extend westward into the North Atlantic; values of CE are typically higher over the ocean off the west coast of Europe, and the differences in skill for the three methods become even more apparent. For example, over the North Atlantic the NAO can not reconstruct precipitation anomalies in the $45-50^{\circ} \mathrm{N}$ latitudinal band, while the blocking has the best temperature reconstruction over northern Africa. The CE values for zonal wind (shown in Fig. S5) are much higher than those of precipitation and temperature, which is not surprising as all classification methods are based on circulation anomalies. For zonal wind, high CE skill is concentrated in two latitudinal bands for the NAO and blocking, while the jet classification has skill over the whole North Atlantic.

\subsection{Scaling factor beta}

The reconstruction described in Sect. 2.2 assumes that the composite mean precipitation or temperature field for each category is representative of all the days falling into the com- 

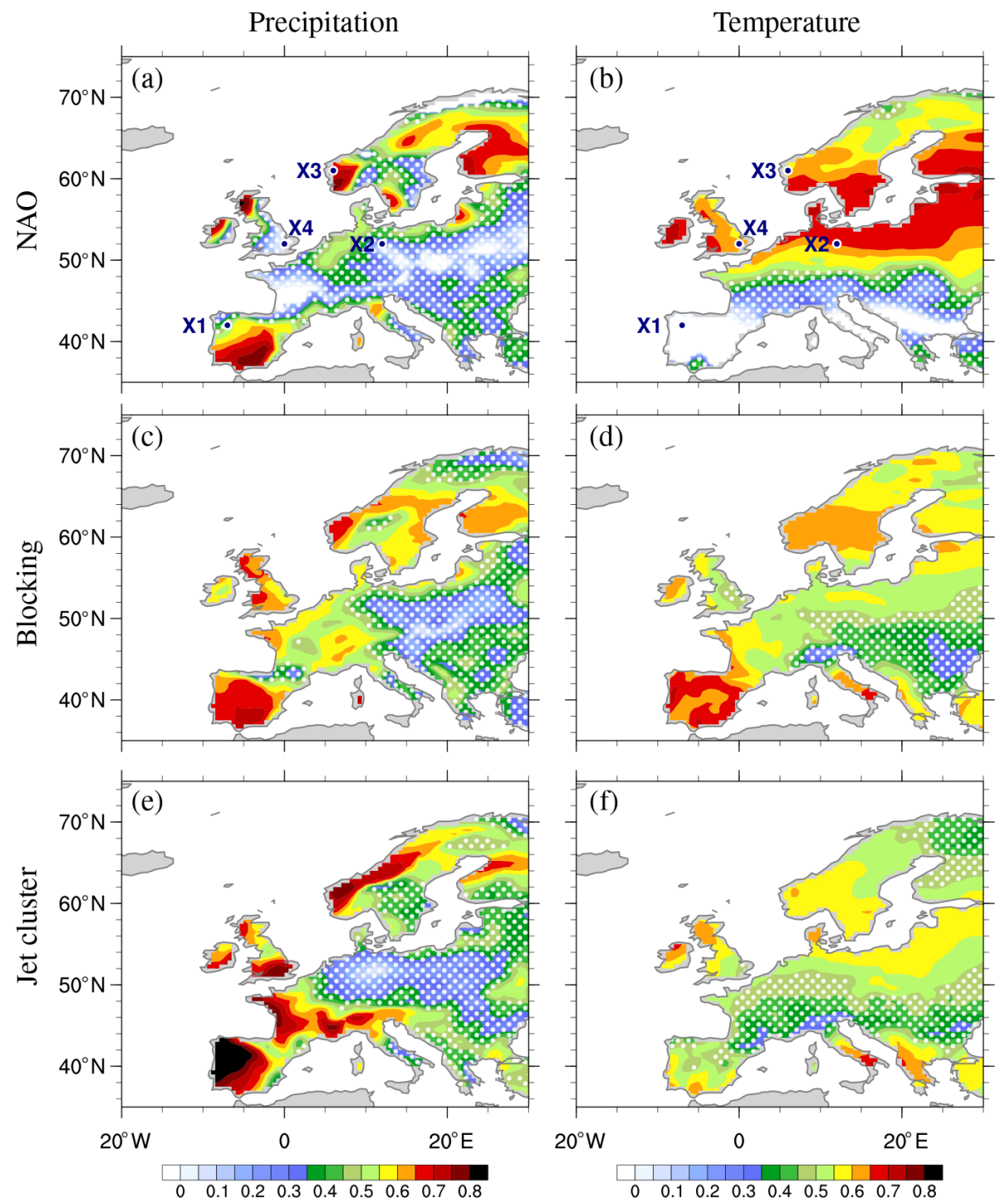

Figure 6. Correlation coefficient between seasonal anomalies of observed and reconstructed precipitation (a, c, e) and temperature (b, d, f) over Europe for two NAO phases (a, b), three blocking categories (c, d), and five jet clusters (e, f). White dots mark regions with correlation below 0.5 . The blue dots labelled X1-4 in (a, b) indicate the four locations shown in Fig. 10.

posites. This assumption works well for variables that follow a Gaussian distribution. However, the assumption does not necessarily hold for fields such as precipitation, which is known to be skewed. Alternative approaches include using the median instead of the mean to define the anomaly patterns, which lessens the influence of extreme values, or estimating the representative anomaly values from a random sample within each category as done by Fereday et al. (2018).

We opt for a different method whereby we adjust the reconstruction a posteriori based on estimates of the anomaly values that best represent each pattern. We start with the approximation of the CE expressed as a function of correlation $r$ between the reconstructed and observed time series at each grid point, as well as amplitude ratio $a$ of their standard de- viations (Eq. 5). It is not possible to improve the correlation $r$, but it is possible to adjust the amplitude ratio $a$ to boost the CE. We do so by calculating the "centre of mass" of the $\mathrm{CE}$ in correlation-amplitude space (with each grid point having a weight of 1), then determining the scaling factor $\beta$ that moves the centre of mass in the $y$ direction so that $a=r$, which maximizes the CE. Thus, the seasonal anomaly of precipitation or temperature from Eq. (1) is

$A_{\mathrm{rec}}(\phi, \lambda, t)=\beta \sum_{i}\left(Y_{i}(\phi, \lambda) \cdot f_{i}(t)\right)$.

For example, for the NAO, the unscaled precipitation reconstruction (Fig. 7a) is shown in $a-r$ space by the black contours in Fig. 8a, with almost all amplitude ratios falling below the $a=r$ line (red). In other words, the amplitudes of 

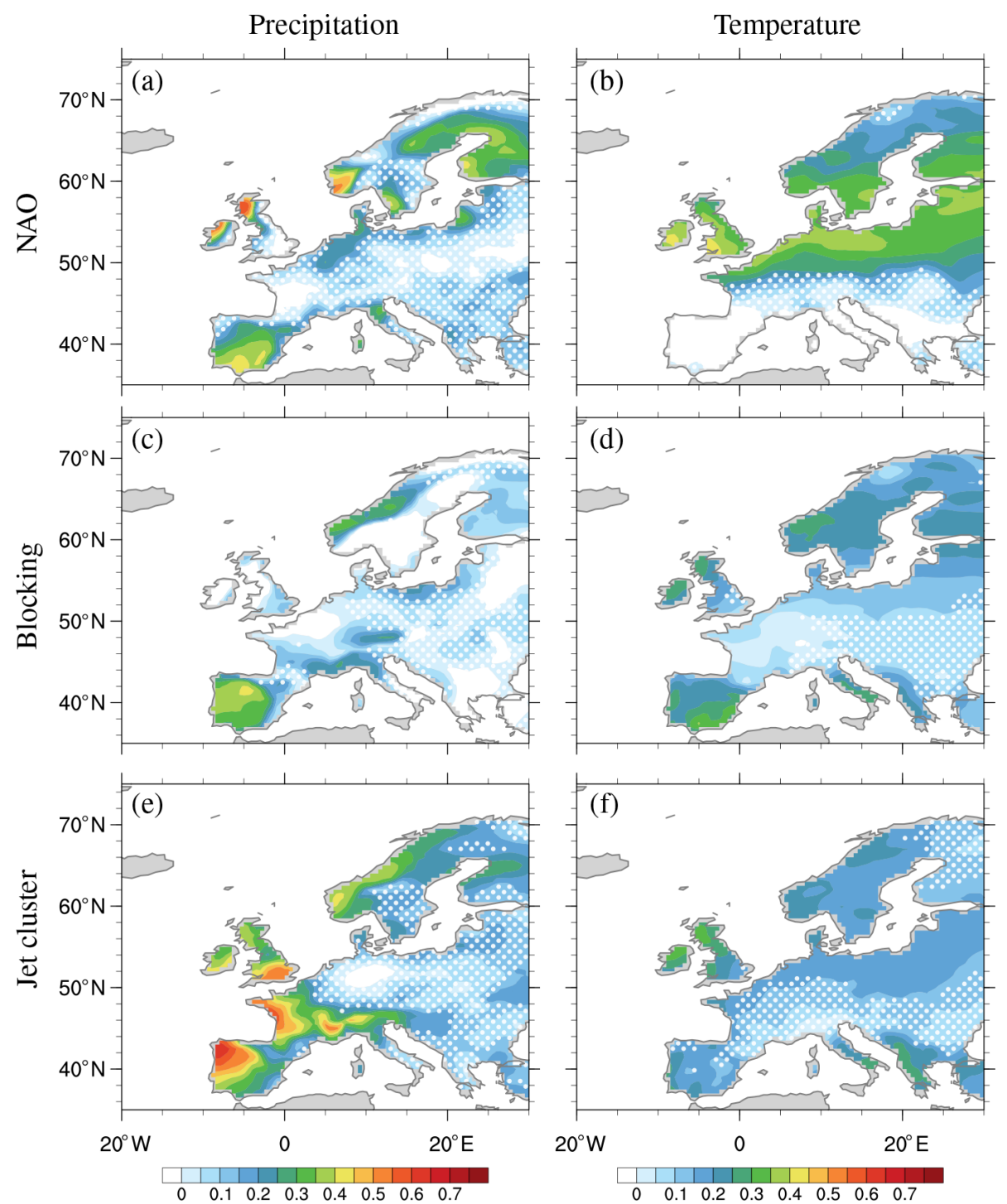

Figure 7. Coefficient of efficiency (CE) for Europe for precipitation (a, c, e) and temperature (b, d, f) for two NAO phases (a, b), three blocking categories $(\mathbf{c}, \mathbf{d})$, and five jet clusters $(\mathbf{e}, \mathbf{f})$. White dots mark regions with correlation below 0.5 (as in Fig. 6).

the reconstructed anomalies tend to be underestimated, even when there is relatively good correlation (right edge of area outlined by black contours). Applying the scaling factor increases the amplitude of these anomalies such that the scaled reconstruction (shown in $a-r$ space by the blue filled contours) has a centre of mass that lies on the $a=r$ line at higher values of $\mathrm{CE}$ (white contours).

Only points with a correlation above 0.5 (which represents approximately the $1 \%$ significance level of a two-tailed $t$ test with 34 degrees of freedom) are used to calculate the scaling factor; this prevents amplitude biases from points with weak correlations, and thus little skill, from affecting the reconstruction ability of points with higher skill. The approximation of the CE given by Eq. (5) requires that the mean of the reconstructed anomalies $(\bar{p})$ be close to zero. This as- sumption is valid for the NAO and jet clusters, but not for the blocking (see Fig. S2). Therefore, the scaling factor $\beta$ is calculated only for the first two classifications. The need for a scaling factor to maximize the reconstruction skill is discussed further in Sect. 4.

Table 2 gives the scaling factors for the reconstructions based on the NAO and jet clusters, indicating that the amplitudes for all variables (precipitation, temperature, and wind) are underestimated by approximately $50 \%(\beta \sim 2)$. Comparing the CE skill score for the unscaled $(\beta=1)$ reconstructions (Fig. 7) vs. the scaled reconstructions (Fig. 9), we see that the scaling substantially improves the seasonal temperature reconstructions over most of the domain, while the improvements are more localized for precipitation. 

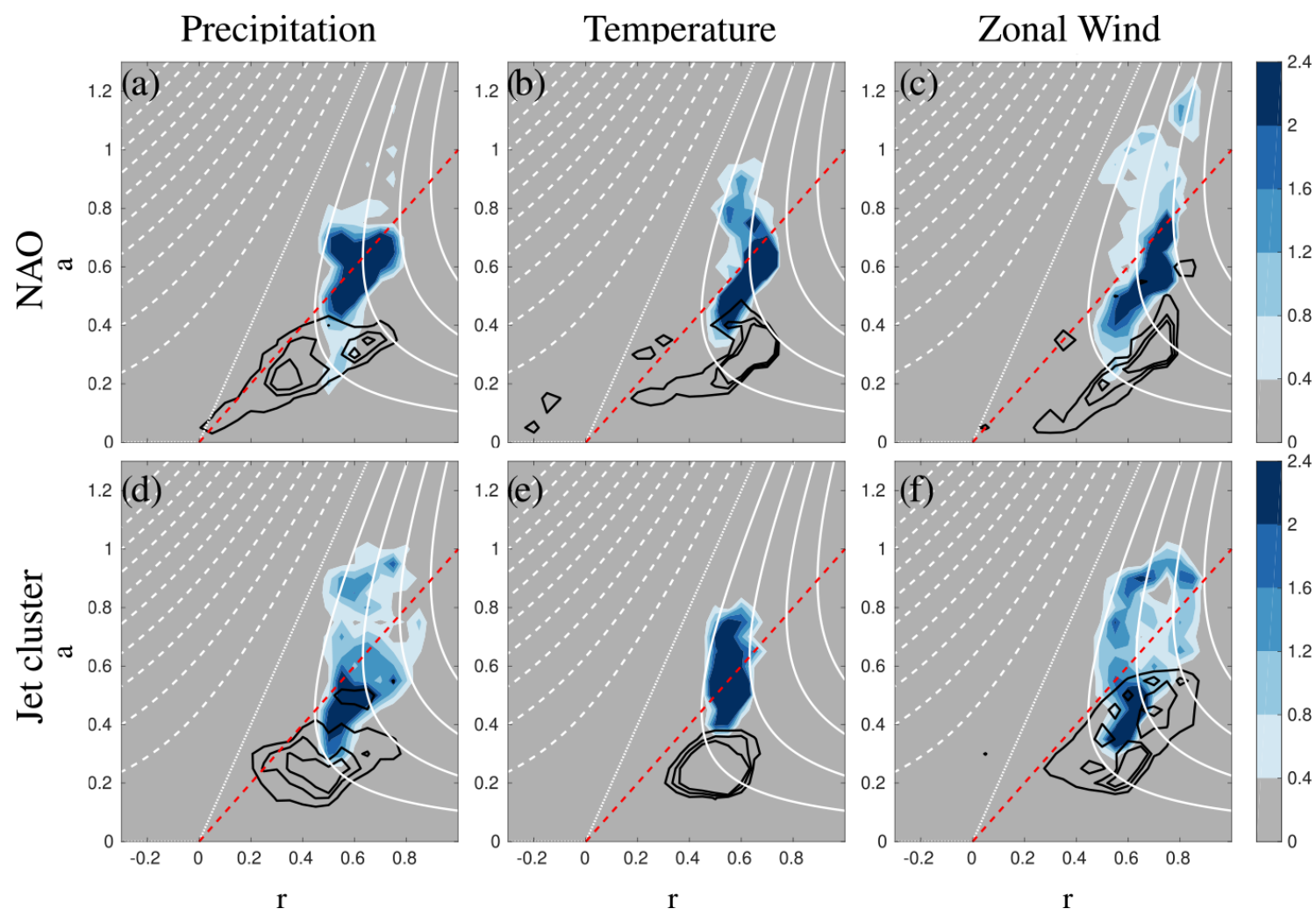

Figure 8. Frequency distribution of correlation $(r)$ vs. $a$, the ratio of the standard deviations of the reconstructed vs. observed seasonal time series (Eq. 6) over Europe (land only) for precipitation (a, d), temperatures (b, e) and zonal wind (c, f) for two NAO phases (a-c), and the five jet clusters (d-f). Black contours $(0.8 \%, 1.6 \%$ and $2.4 \%)$ are for unscaled reconstructed time series, while the shading is the shifted (scaled) values applied only to grid points with correlation greater than 0.5 . Data are normalized by the number of points in each distribution, and units are given in percent. White lines are isolines of CE following Eq. (5) in 0.2 intervals (0 line dotted; positive solid, and negative dashed), while the red line shows the maximization of CE as function of $r$ (i.e. the $r=a$ line).

Table 2. Scaling factors $\beta$ for two NAO phases and five jet clusters for grid points over Europe (only land) and only with correlation larger than 0.5 .

\begin{tabular}{lccc}
\hline Scaling factor $\beta$ & Precipitation & Temperatures & $\begin{array}{c}\text { Zonal } \\
\text { wind }\end{array}$ \\
\hline Two NAO phases & 1.8 & 1.9 & 1.9 \\
Five jet clusters & 1.8 & 2.2 & 1.7 \\
\hline
\end{tabular}

The skill of the seasonal reconstructions is perhaps most easily illustrated for specific locations of interest across Europe (Galicia in Spain, Berlin, Bergen, and London, indicated by X1-4 in Fig. 6a and b). Figure 10 shows the observed precipitation and temperature anomalies (black, ERA-Interim) and reconstructions for these locations (scaled for the NAO in grey and jet clusters in red, unscaled for blocking in blue; the unscaled anomaly magnitudes are expected to be underestimated). Precipitation is well reconstructed for Galicia (Fig. 10a), Bergen (Fig. 10e), and London (Fig. 10g) using the five jet clusters (red): correlations between reconstructed and observed anomalies range from 0.76 to 0.87 . None of the methods reconstruct well the seasonal precipitation anomalies in Berlin (Fig. 10c); this is not surprising, given there is little variability in the seasonal averaged precipitation. In terms of temperature, the three methods produce skilful temperature reconstructions for all locations but Galicia, where the NAO has no skill.

\section{Discussion}

We have shown in this paper that the skill of various classification methods in reconstructing European seasonal surface precipitation and temperature anomalies is strongly dependent on the region. There is no one method that works best for all regions and variables, and to maximize the coefficient of efficiency of the seasonal reconstructions a scaling factor of approximately 2 is required.

Considering correlation (Fig. 6) and the unscaled CE (Eq. 3 and Fig. 7), one might expect the skill of a reconstruction to improve with the number of basis functions (patterns) used. For example, more of the interannual variability should 

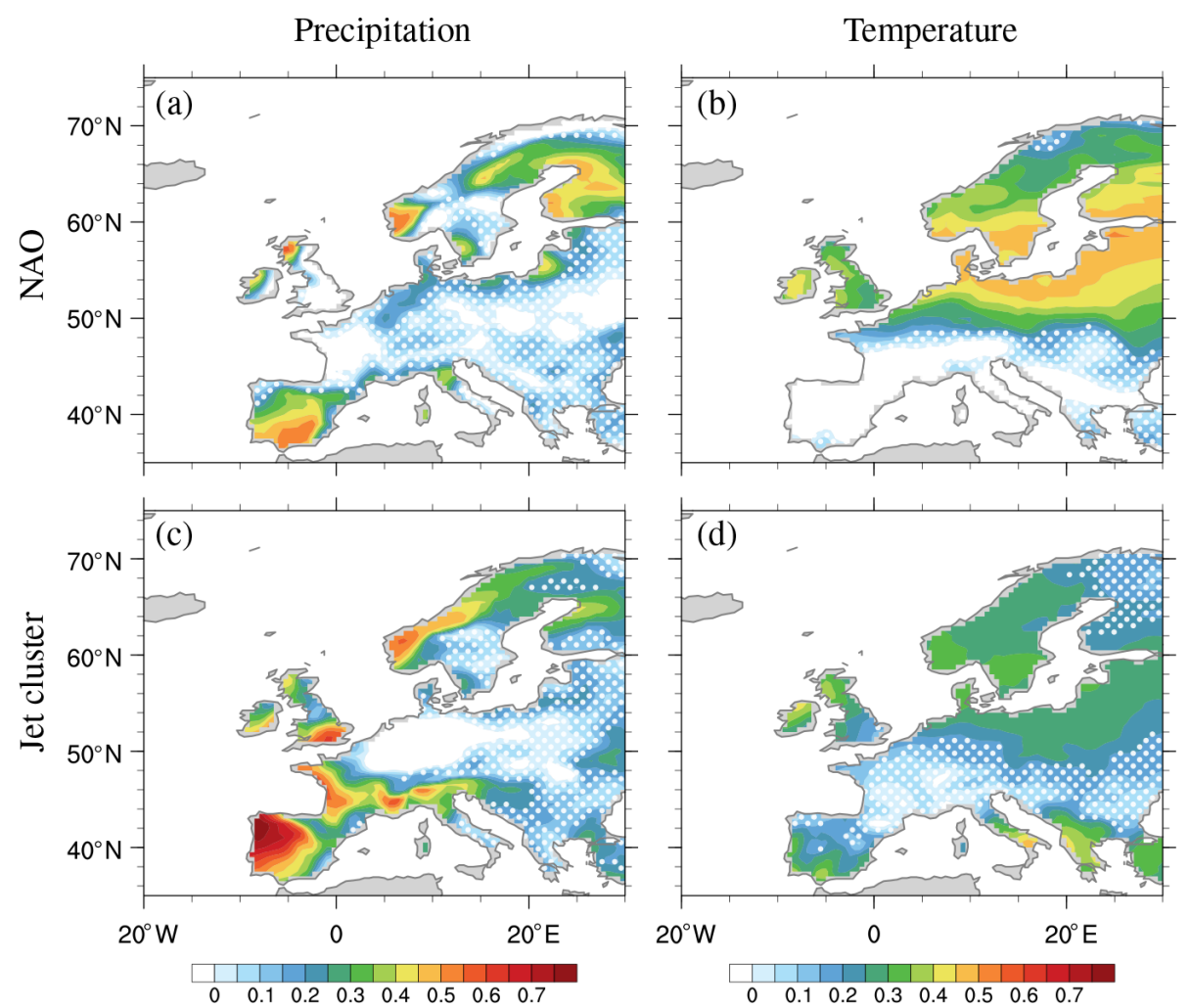

Figure 9. CE scaled reconstructions of precipitation (a, c) and temperature (b, d) for two NAO phases (a, b), and five jet clusters (c, d). Scaling factors are calculated using only points with correlation $r>0.5$ (white dots marks regions with $r<0.5$ ). The scaling coefficients are shown in Table 2.

be captured by the jet clusters (five patterns) than blocking (three patterns) or the NAO (only two patterns). While this is mostly true for precipitation, it does not always apply for temperature. In northeastern Europe and Scandinavia, the NAO outperforms the other classification methods. A possible explanation might lie in the different domains used to define the classification patterns: the region used for the jet clusters is much smaller than that for the NAO (Fig. 1), with an eastern limit at the Greenwich prime meridian $\left(0^{\circ}\right)$ for the jet cluster while the domain used to define the NAO extends $30^{\circ}$ further east and includes Europe. Thus, it is not so surprising that the NAO is better able to capture the seasonal anomalies over central and eastern Europe, as circulation variability over these regions is integrated into the NAO definition. In fact, it is rather remarkable that so much of the seasonal precipitation and temperature signal over Europe can be inferred just by knowing the circulation over the North Atlantic Ocean (i.e. using the jet clusters). In some regions the seasonal anomalies reconstructed from the blocking patterns are similarly or even more skilful in term of correlation than those using the jet regimes (e.g. precipitation over France), but they have much lower CE scores because the sum of the residual anomaly pattern is not zero (see Fig. S2). This behaviour can be partly understood knowing that nonblocked days encompass days with weak winds as well as days with strong zonal wind; the composite mean of those days (Fig. S1) might sum up to zero over 35 years, but this does not have to be true for a season.

One might also expect the skill of a reconstruction to depend on the amount of information included, i.e. the number of days per season used. In our reconstructions, we include only the days that distinctly belong to a certain basis function within each classification method. Interestingly, this sums to about half of the total days in the record, regardless of method. One could of course use more information, but this does not necessarily improve the reconstruction skill. Indeed, a sensitivity test (see Supplement Sect. A) shows that including all days for the jet classification leads to very little improvement in the CE score. A similar example is shown by Fereday et al. (2018), who used 30 SLP patterns (i.e. many more basis functions) and all days to reconstruct winter precipitation. The correlation between their reconstructed and the observed precipitation was of $\sim 0.8$ over northern and southern Europe. Averaging our results over the same regions, we obtain lower but comparable correlations between observed and reconstructed precipitation: $0.54-0.78$ for the northern region (Fig. S6, blue) and 0.53-0.66 for the southern region (Fig. S6, red).

All the reconstructions underestimate the amplitude of the observed precipitation and temperature anomalies. This con- 
Precipitation
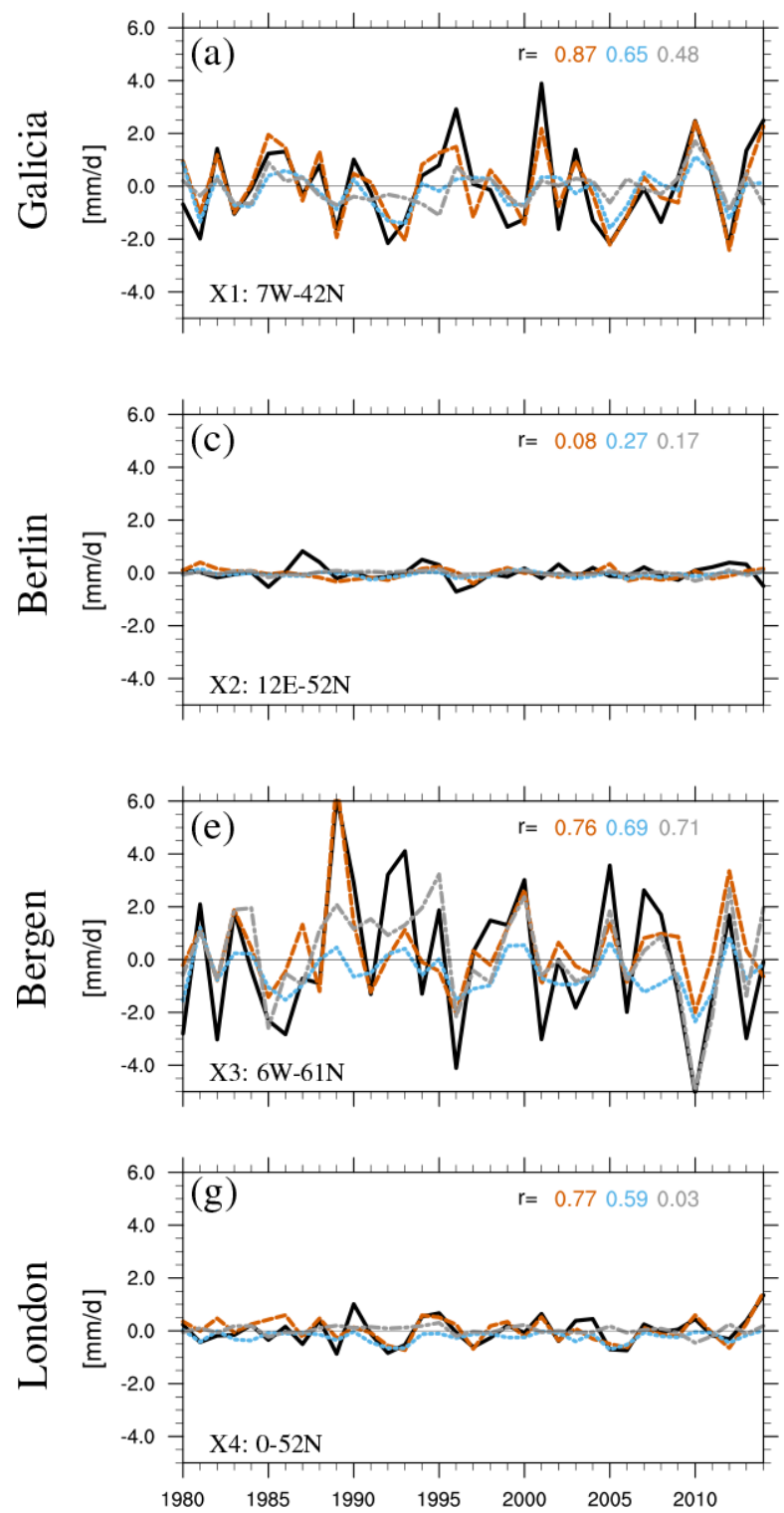

Temperature
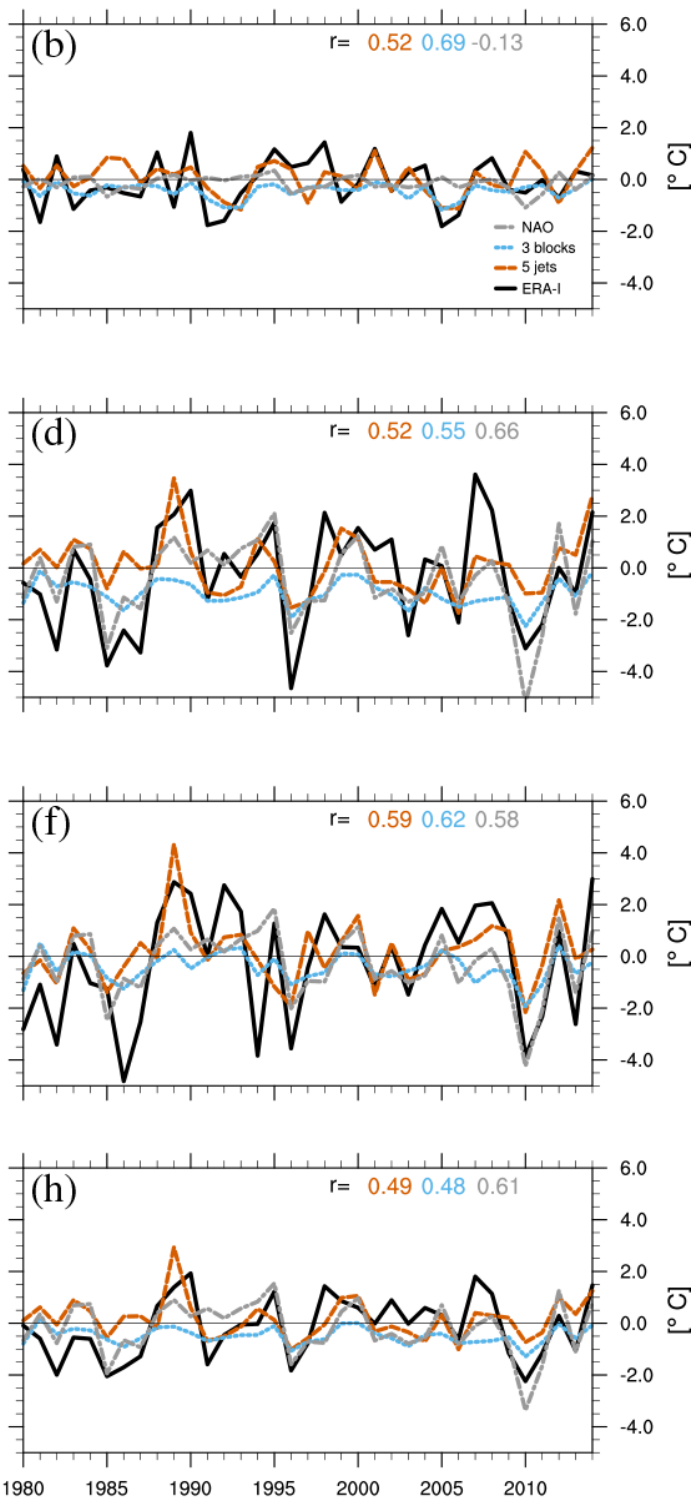

Figure 10. Time series of DJF precipitation $\left(\mathbf{a}, \mathbf{c}, \mathbf{e}, \mathbf{g}\right.$, in $\mathrm{mmd}^{-1}$, averaged over a season) and temperature anomalies $\left(\mathbf{b}, \mathbf{d}, \mathbf{f}, \mathbf{h}\right.$, in $\left.{ }^{\circ} \mathrm{C}\right)$ for four locations shown in Fig. 6: Galicia (X1, a, b), Berlin (X2, c, d), Bergen (X3, e, f), and London (X4, g, h). The magnitude of the anomalies has been multiplied by the scaling factor $\beta$ for the NAO and jet, but not for the blocking (see main text). Correlations ( $r$ ) between the time series of observed (ERA-Interim - ERA-I) and reconstructed anomalies for the different methods are shown using the colour legend in (b). Please note that the multiplication by the scaling factor has no effect on correlations. The same $y$ scale is used in each panel to highlight the large differences in magnitude and variability across the different locations.

tributes to the low CE skill score in many regions in Europe, despite relatively high correlations between the reconstruction and reanalysis data. The CE skill score for precipitation and temperature reconstructions for the NAO and jet improves when we introduce a scaling factor $(\beta)$ of $\sim 2$ to the composite mean anomaly patterns. A possible reason for the underestimation of the reconstructed amplitude is the large variability within each composite. For example for an S-jet day, we expect precipitation to be enhanced over the Iberian Peninsula (cf. Fig. 3), but the exact location where the precipitation peaks, which is likely linked to the passage of a specific cyclone, varies from case to case (i.e. cyclones do not have the exact same path). Therefore, at each grid point the standard deviation within each composite can be quite large (Figs. S7 and S8). To gain some insight into why this scaling factor is required, we repeat the NAO seasonal tem- 
perature reconstruction using regression techniques instead of composites. Using a simple ordinary linear regression on daily NAO and temperature values, we find relationships $\left({ }^{\circ} \mathrm{C}\right.$ per unit anomalous NAO index) very similar to those found by the composite method shown in Fig. 4. A reconstruction is then made by multiplying the regression pattern by the mean NAO value for each season. In this regression approach, all days are used in the reconstruction (compared to about half the days in the composite approach). However, the correlation and $\mathrm{CE}$ values of the two reconstructions are very similar, and both require a scaling factor to maximize the skill. This suggests that the need for a scaling factor is not linked to the omission of information (i.e. the neutral NAO or undefined days).

If, instead, the regression between daily temperature anomalies and daily NAO values is calculated using a weighted orthogonal distance regression (using the Python package scipy.odr), the regression relationship changes - the slope of the linear fit generally increases. An example is shown in Fig. 11 for Bergen (cf. blue regression line for ordinary least squares, black regression line for orthogonal distance). This increase in regression slope means that the reconstruction amplitudes increase, and there is less need for a scaling factor. The weighted orthogonal distance regression takes into account "noise" in both the temperature and the NAO values, while ordinary least squares considers the values of the independent variable (in this case the NAO) to be exact (e.g. Wu and Yu, 2018). This noise may be related to a lag-lead relationship between circulation patterns and surface weather anomalies and/or uncertainty in the connections between the NAO circulation anomalies and surface temperature. In Fig. 11 the mean composite values for this grid box are shown by the cyan markers, and they fall on the ordinary least squares regression line. The median composite values are also shown in purple, demonstrating that using the composite median would not remove the need for the scaling factor. This suggests that the need for the scaling factor in the composite and ordinary least squares regression reflects the large variability in temperature and precipitation within each classification pattern (cf. Figs. S7 and S8).

Finally, the ability to reconstruct precipitation and temperature might be affected by extreme events. For example, if a single extreme precipitation event is responsible for the lion's share of precipitation in a specific season, we would not expect a skilful reconstruction of the seasonal anomaly using the average precipitation signals associated with each basis function. The effect of extreme events varies regionally, as shown for summer temperatures by Röthlisberger et al. (2020). It would therefore be interesting to investigate to what extent extreme events influence the seasonal precipitation and temperature anomalies over Europe and how these events are related to circulation anomalies.

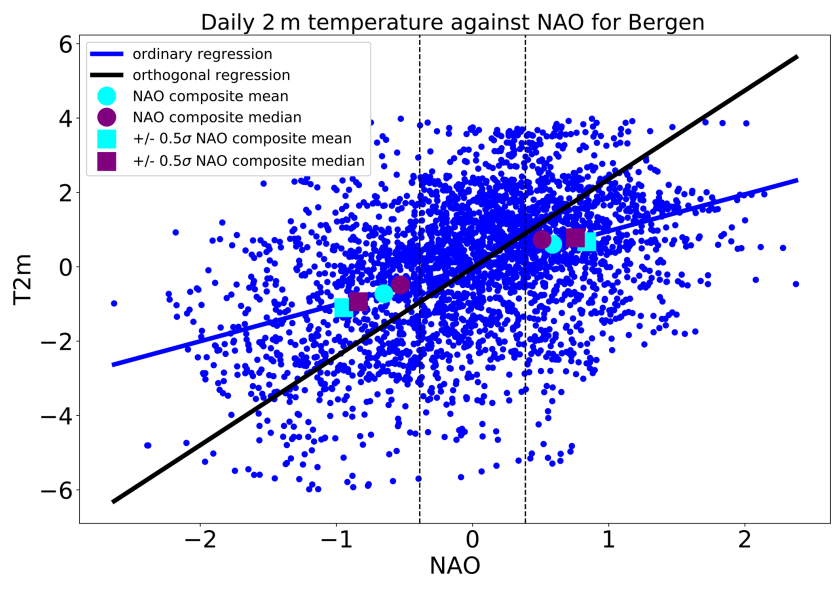

Figure 11. Illustration of the different regression slopes from ordinary (blue) and weighted orthogonal (black) regression on daily values of temperature (T2m) the grid box closest to Bergen, Norway, plotted against NAO. The cyan (purple) circles and squares show composite mean (median) values for all positive/negative NAO days and all positive/negative NAO days with $|\mathrm{NAO}|>0.5 \sigma$.

\section{Concluding remarks}

In this study, we investigate how well seasonal anomalies in European precipitation and temperature can be reconstructed based on the frequency of circulation patterns defined using three different classifications: the NAO index, blocking, and the configuration of the North Atlantic jet stream.

The skill of the various classifications in reconstructing seasonal anomalies depends on the variable and region of interest. For the NAO and jet clusters, the regions of high skill for precipitation are rather different than for temperature (see Fig. 9). Precipitation in western Europe is particularly well reconstructed, with many coastal and mountainous areas showing coefficient of efficiency values for scaled precipitation greater than 0.5 (Fig. 9). For these areas, precipitation in winter is directly linked to the propagation of storms travelling from the Atlantic (Hawcroft et al., 2012; Pfahl et al., 2014), which is to first order set by large-scale circulation variability. Still, the relationship between circulation and precipitation is far from straightforward, seen by the fact that in some places precipitation is reconstructed with comparable (high) skill by all three methods (e.g. Bergen, Norway), while in other places one method performs worse than others (e.g. NAO in Galicia). For temperature, circulation influences the horizontal and vertical advection of air, allowing a simple index like the NAO to provide skilful reconstructions across much of northern Europe. However, over France temperatures are better captured by the blocking reconstruction. In southern and inland regions (e.g. Berlin, Germany), none of the methods provides skilful reconstructions of temperature or precipitation, suggesting that factors unrelated to circulation are important, for example radiative forcing (e.g. 
clear vs. cloudy, Trigo et al., 2004), soil moisture coupling (Fischer et al., 2007), or snow-albedo feedback.

In the end, no single classification metric emerges as providing "the best" reconstruction of both precipitation and temperature across all regions. The three circulation metrics - jet clusters, blocking, and NAO - are clearly connected but emphasize different aspects of the large-scale flow with different implications for surface climate. The results presented here can provide guidance on which classification method is most suitable for linking regional climate to circulation variability. Through this approach, one may gain insight into the surface impacts of weather events over a range of timescales. Regime-based reconstruction may prove useful in extended range predictability (Kim et al., 2016; Scaife et al., 2014) and in assessing changes in the frequency of weather patterns that constitute the changes in the climatology under anthropogenic forcing.

Code and data availability. ERA-Interim data can be downloaded from the ECMWF page https://apps.ecmwf.int/datasets/ data/interim-full-daily/levtype $=$ sfc/ (last access: 14 May 2020) (ECMWF, 2020; Dee et al., 2011). The NAO index was downloaded from NOAA ftp://ftp.cpc.ncep.noaa.gov/cwlinks/norm. daily.nao.index.b500101.current.ascii (last access: 14 May 2020) (NOAA, 2020). The method to identify blocking is described in Scherrer et al. (2006) and for jet clusters in Madonna et al. (2017). The winter time series used in this study are available at https://doi.org/10.5281/zenodo.4011886 (Madonna, 2021).

Supplement. The supplement related to this article is available online at: https://doi.org/10.5194/wcd-2-777-2021-supplement.

Author contributions. DSB and EM designed the study. EM performed most of the analysis, with RHW contributing the NAO regression analysis. All authors contributed to the interpretation and discussion of the results and the writing of the paper.

Competing interests. Camille Li and David S. Battisti are members of the editorial board of the journal.

Disclaimer. Publisher's note: Copernicus Publications remains neutral with regard to jurisdictional claims in published maps and institutional affiliations.

Acknowledgements. Erica Madonna and Camille Li acknowledge funding from the Research Council of Norway (Nansen Legacy grant no. 276730). Rachel $\mathrm{H}$. White received funding from the $\mathrm{Eu}-$ ropean Union's Horizon 2020 research and innovation programme under the Marie Skłodowska-Curie grant agreement no. 797961 and from the Tamaki Foundation. ECMWF and NOAA are acknowledged for providing the ERA-Interim reanalyses and NAO data, re- spectively. We thank two anonymous reviewers for their constructive comments that improved the quality of this article.

Financial support. This research has been supported by the Research Council of Norway (grant no. 276730) and H2020 Marie Skłodowska-Curie Actions (grant no. 797961).

Review statement. This paper was edited by Paulo Ceppi and reviewed by two anonymous referees.

\section{References}

Athanasiadis, P. J., Wallace, J. M., and Wettstein, J. J.: Patterns of wintertime jet stream variability and their relation to the storm tracks, J. Atmos. Sci., 67, 1361-1381, 2010.

Battisti, D. S., Vimont, D. J., and Kirtman, B. P.: 100 Years of progress in understanding the dynamics of coupled atmosphere/ocean variability, Meteor. Mon., 59, 8.1-8.57, 2019.

Briffa, K. R., Jones, P. D., and Schweingruber, F. H.: Tree-Ring Density Reconstructions of Summer Temperature Patterns across Western North America since 1600, J. Climate, 5, 735-754, 1992.

Bürger, G.: On the verification of climate reconstructions, Clim. Past, 3, 397-409, https://doi.org/10.5194/cp-3-397-2007, 2007.

Cassou, C.: Intraseasonal interaction between the Madden-Julian oscillation and the North Atlantic Oscillation, Nature, 455, 523527, 2008.

Cattiaux, J., Douville, H., and Peings, Y.: European temperatures in CMIP5: origins of present-day biases and future uncertainties, Clim. Dynam., 41, 2889-2907, 2013.

Christiansen, B.: Atmospheric circulation regimes: Can cluster analysis provide the number?, J. Climate, 20, 2229-2250, 2007.

Corte-Real, J., Zhang, X., and Wang, X.: Large-scale circulation regimes and surface climatic anomalies over the Mediterranean, Int. J. Climatol., 15, 1135-1150, 1995.

Cortesi, N., Torralba, V., González-Reviriego, N., Soret, A., and Doblas-Reyes, F. J.: Characterization of European wind speed variability using weather regimes, Clim. Dynam., 53, 49614976, 2019.

Davini, P., Cagnazzo, C., Fogli, P. G., Manzini, E., Gualdi, S., and Navarra, A.: European blocking and Atlantic jet stream variability in the NCEP/NCAR reanalysis and the CMCC-CMS climate model, Clim. Dynam., 43, 71-85, 2014.

Dee, D. P., Uppala, S. M., Simmons, A. J., Berrisford, P., Poli, P., Kobayashi, S., Andrae, U., Balmaseda, M. A., Balsamo, G., Bauer, P., Bechtold, P., Beljaars, A. C. M., van de Berg, L., Bidlot, J., Bormann, N., Delsol, C., Dragani, R., Fuentes, M., Geer, A. J., Haimberger, L., Healy, S. B., Hersbach, H., Hólm, E. V., Isaksen, L., Kållberg, P., Köhler, M., Matricardi, M., McNally, A. P., Monge-Sanz, B. M., Morcrette, J.-J., Park, B.K., Peubey, C., de Rosnay, P., Tavolato, C., Thépaut, J.-N., and Vitart, F.: The ERA-Interim reanalysis: configuration and performance of the data assimilation system, Q. J. Roy. Meteor. Soc., 137, 553-597, 2011. 
Dorrington, J. and Strommen, K.: Jet Speed Variability Obscures Euro-Atlantic Regime Structure, Geophys. Res. Lett., 47, e2020GL087907, https://doi.org/10.1029/2020GL087907, 2020.

ECMWF: ERA Interim, Daily, available at: https://apps.ecmwf. int/datasets/data/interim-full-daily/levtype $=\mathrm{sfc} /$, last access: 14 May 2020.

Falkena, S. K., de Wiljes, J., Weisheimer, A., and Shepherd, T. G.: Revisiting the identification of wintertime atmospheric circulation regimes in the Euro-Atlantic sector, Q. J. Roy. Meteor. Soc., 146, 2801-2814, 2020.

Fereday, D., Chadwick, R., Knight, J., and Scaife, A. A.: Atmospheric Dynamics is the Largest Source of Uncertainty in Future Winter European Rainfall, J. Climate, 31, 963-977, 2018.

Fischer, E. M., Seneviratne, S. I., Vidale, P. L., Lüthi, D., and Schär, C.: Soil moisture-atmosphere interactions during the 2003 European summer heat wave, J. Climate, 20, 5081-5099, 2007.

Grams, C. M., Beerli, R., Pfenninger, S., Staffell, I., and Wernli, H.: Balancing Europe's wind-power output through spatial deployment informed by weather regimes, Nat. Clim. Change, 7, 557$562,2017$.

Hawcroft, M., Shaffrey, L., Hodges, K., and Dacre, H.: How much Northern Hemisphere precipitation is associated with extratropical cyclones?, Geophys. Res. Lett., 39, L24809, https://doi.org/10.1029/2012GL053866, 2012.

Hoskins, B. J. and Ambrizzi, T.: Rossby wave propagation on a realistic longitudinally varying flow, J. Atmos. Sci., 50, 1661-1671, 1993.

Hurrell, J. W.: Decadal trends in the North Atlantic Oscillation: regional temperatures and precipitation, Science, 269, 676-679, 1995.

Hurrell, J. W., Kushnir, Y., Ottersen, G., and Visbeck, M.: An overview of the North Atlantic Oscillation, Geophys. Monograph-American Geophys. Union, 134, 1-36, 2003.

Jerez, S., Trigo, R. M., Vicente-Serrano, S. M., Pozo-Vázquez, D., Lorente-Plazas, R., Lorenzo-Lacruz, J., Santos-Alamillos, F., and Montávez, J.: The impact of the North Atlantic Oscillation on renewable energy resources in southwestern Europe, J. Appl. Meteorol. Clim., 52, 2204-2225, 2013.

Kim, G., Ahn, J.-B., Kryjov, V. N., Sohn, S.-J., Yun, W.-T., Graham, R., Kolli, R. K., Kumar, A., and Ceron, J.-P.: Global and regional skill of the seasonal predictions by WMO Lead Centre for Long-Range Forecast Multi-Model Ensemble, Int. J. Climatol., 36, 1657-1675, 2016.

Lavaysse, C., Vogt, J., Toreti, A., Carrera, M. L., and Pappenberger, F.: On the use of weather regimes to forecast meteorological drought over Europe, Nat. Hazards Earth Syst. Sci., 18, $3297-$ 3309, https://doi.org/10.5194/nhess-18-3297-2018, 2018.

Lesk, C., Rowhani, P., and Ramankutty, N.: Influence of extreme weather disasters on global crop production, Nature, 529, 84-87, 2016.

Madonna, E.: North Atlantic jet stream clusters: daily and seasonal occurence (1.0), Zenodo [data set], https://doi.org/10.5281/zenodo.4011886, 2021.

Madonna, E., Li, C., Grams, C. M., and Woollings, T.: The link between eddy-driven jet variability and weather regimes in the North Atlantic-European sector, Q. J. Roy. Meteor. Soc., 143, 2960-2972, https://doi.org/10.1002/qj.3155, 2017.

Madonna, E., Li, C., and Wettstein, J. J.: Suppressed eddy driving during southward excursions of the North Atlantic jet on synoptic to seasonal time scales, Atmos. Sci. Lett., 20, e937, https://doi.org/10.1002/asl.937, 2019.

Michelangeli, P.-A., Vautard, R., and Legras, B.: Weather regimes: Recurrence and quasi stationarity, J. Atmos. Sci., 52, 1237-1256, 1995.

Molteni, F., Tibaldi, S., and Palmer, T.: Regimes in the wintertime circulation over northern extratropics. I: Observational evidence, Q. J. Roy. Meteor. Soc., 116, 31-67, 1990.

Nash, J. E. and Sutcliffe, J. V.: River flow forecasting through conceptual models part I - A discussion of principles, J. Hydrol., 10, 282-290, 1970.

NOAA - National Oceanic and Atmospheric Administration: Daily NAO index since January 1950, available at: ftp://ftp.cpc.ncep. noaa.gov/cwlinks/norm.daily.nao.index.b500101.current.ascii, last access: 14 May 2020.

Pfahl, S. and Wernli, H.: Quantifying the relevance of atmospheric blocking for co-located temperature extremes in the Northern Hemisphere on (sub-) daily time scales, Geophys. Res. Lett., 39, L12807, https://doi.org/10.1029/2012GL052261, 2012.

Pfahl, S., Madonna, E., Boettcher, M., Joos, H., and Wernli, H.: Warm conveyor belts in the ERA-Interim dataset (1979-2010). Part II: Moisture origin and relevance for precipitation, J. Climate, 27, 27-40, 2014.

Qian, B., Corte-Real, J., and Xu, H.: Is the North Atlantic Oscillation the most important atmospheric pattern for precipitation in Europe?, J. Geophys. Res.-Atmos., 105, 11901-11910, 2000.

Rex, D. F.: Blocking action in the middle troposphere and its effect upon regional climate, Tellus, 2, 275-301, 1950.

Rogers, J. C.: North Atlantic storm track variability and its association to the North Atlantic Oscillation and climate variability of northern Europe, J. Climate, 10, 1635-1647, 1997.

Röthlisberger, M., Sprenger, M., Flaounas, E., Beyerle, U., and Wernli, H.: The substructure of extremely hot summers in the Northern Hemisphere, Weather Clim. Dynam., 1, 45-62, https://doi.org/10.5194/wcd-1-45-2020, 2020.

Santos, J. A., Belo-Pereira, M., Fraga, H., and Pinto, J. G.: Understanding climate change projections for precipitation over western Europe with a weather typing approach, J. Geophys. Res.Atmos., 121, 1170-1189, 2016.

Scaife, A. A., Arribas, A., Blockley, E., Brookshaw, A., Clark, R. T., Dunstone, N., Eade, R., Fereday, D., Folland, C. K., Gordon, M., Hermanson, L., Knight, J. R., Lea, D. J., MacLachlan, C., Maidens, A., Martin, M., Peterson, A. K., Smith, D., Vellinga, M., Wallace, E., Waters, J., and Williams, A.: Skillful long-range prediction of European and North American winters, Geophys. Res. Lett., 41, 2514-2519, 2014.

Scherrer, S. C., Croci-Maspoli, M., Schwierz, C., and Appenzeller, C.: Two-dimensional indices of atmospheric blocking and their statistical relationship with winter climate patterns in the Euro-Atlantic region, Int. J. Climatol., 26, 233-249, 2006.

Sillmann, J. and Croci-Maspoli, M.: Present and future atmospheric blocking and its impact on European mean and extreme climate, Geophys. Res. Lett., 36, L10702, https://doi.org/10.1029/2009GL038259, 2009.

Sousa, P. M., Trigo, R. M., Barriopedro, D., Soares, P. M., Ramos, A. M., and Liberato, M. L.: Responses of European precipitation distributions and regimes to different blocking locations, Clim. Dynam., 48, 1141-1160, 2017. 
Treidl, R., Birch, E., and Sajecki, P.: Blocking action in the Northern Hemisphere: A climatological study, Atmos. Ocean, 19, 1-23, 1981.

Trigo, R., Trigo, I., DaCamara, C., and Osborn, T.: Climate impact of the European winter blocking episodes from the NCEP/NCAR Reanalyses, Clim. Dynam., 23, 17-28, 2004.

van der Wiel, K., Bloomfield, H. C., Lee, R. W., Stoop, L. P., Blackport, R., Screen, J. A., and Selten, F. M.: The influence of weather regimes on European renewable energy production and demand, Environ. Res. Lett., 14, 094010, https://doi.org/10.1088/17489326/ab38d3, 2019.

Vautard, R.: Multiple weather regimes over the North Atlantic: Analysis of precursors and successors, Mon. Weather Rev., 118, 2056-2081, 1990.

Wang, J., Emile-Geay, J., Guillot, D., Smerdon, J. E., and Rajaratnam, B.: Evaluating climate field reconstruction techniques using improved emulations of real-world conditions, Clim. Past, 10, 119, https://doi.org/10.5194/cp-10-1-2014, 2014.

Wanner, H., Brönnimann, S., Casty, C., Gyalistras, D., Luterbacher, J., Schmutz, C., Stephenson, D. B., and Xoplaki, E.: North Atlantic Oscillation - concepts and studies, Surv. Geophys., 22, 321-381, 2001.
Wettstein, J. J. and Wallace, J. M.: Observed patterns of month-tomonth storm-track variability and their relationship to the background flow, J. Atmos. Sci., 67, 1420-1437, 2010.

Wirth, V., Riemer, M., Chang, E. K., and Martius, O.: Rossby wave packets on the midlatitude waveguide - A review, Mon. Weather Rev., 146, 1965-2001, 2018.

Woollings, T., Hoskins, B., Blackburn, M., and Berrisford, P.: A new Rossby wave-breaking interpretation of the North Atlantic Oscillation, J. Atmos. Sci., 65, 609-626, 2008.

Woollings, T., Hannachi, A., and Hoskins, B.: Variability of the North Atlantic eddy-driven jet stream, Q. J. Roy. Meteor. Soc., 136, 856-868, 2010.

Woollings, T., Czuchnicki, C., and Franzke, C.: Twentieth century North Atlantic jet variability, Q. J. Roy. Meteor. Soc., 140, 783791, 2014.

$\mathrm{Wu}$, C. and Yu, J. Z.: Evaluation of linear regression techniques for atmospheric applications: the importance of appropriate weighting, Atmos. Meas. Tech., 11, 1233-1250, https://doi.org/10.5194/amt-11-1233-2018, 2018.

Zveryaev, I. I.: Seasonality in precipitation variability over Europe, J. Geophys. Res.-Atmos., 109, D05103, https://doi.org/10.1029/2003JD003668, 2004. 